\title{
Role of Information Professional for the Growth of Altmetrics in the Digital Era
}

\author{
P. Sankar ${ }^{1}$ and E. S. Kavitha ${ }^{2}$ \\ ${ }^{1}$ Research Scholar,Department of Library and Information Science, Periyar University, Salem and \\ Librarian, SNT Global Academy of Management Studies and Technology, Coimbatore, Tamil Nadu, India \\ ${ }^{2}$ Assistant Professor, Department of Library and Information Science, Periyar University, Salem, Tamil Nadu, India \\ E-mail: amulsankar@gmail.com,kavithaesk@gmail.com
}

\begin{abstract}
Any librarian in this field will need to continue not only filling these roles, but also ensuring that they themselves are part of the conversation as it moves forward and staying up-to-date with developments within this area. The concept of library involvement pertaining to metrics did not originate with altmetrics. Impact Factor was originally created primarily for use by librarians in making collection development and retention decisions. Libraries continue to bear primary responsibility for the acquisition of bibliometrics tools, most notably Web of Science, Journal Citation Reports, and Scopus, as well as the training of people in their use. As a result, librarians are already familiar with providing support for these tools, so it makes sense that librarians have expanded to support the variety of altmetrics sources and tools. Additionally, librarians serve as natural leaders when it comes to altmetrics, not only due to familiarity with resources, but also because of the relationships they maintain with several disparate groups. The article detailed about the various tools, section, evaluation methods in which libraries and librarians are supporting and interacting with altmetrics.
\end{abstract}

\section{I.INTRODUCTION TO ALTMETRICS}

Altmetrics is the creation and study of new metrics based on the Social Web for analyzing, and informing scholarship. According to Galliga, F. \& Dyas-Correia, S (2013) Altmetrics defined as "Altmetrics are new measurements for the impact of scholarly content, based on how far and wide it travels through the social Web (like Twitter), social bookmarking (e.g. CiteULike) and collaboration tools (such as Mendeley) ... What altmetrics hope to do is provide an alternative measure of impact, distinct from the Journal Impact Factor, which has been categorically misused and is unable to respond to the digital environment that scholarship takes place in today"

\section{A.Altmetrics Tools and Software to increase visibility}

a. ORCID: ORCID provides a persistent digital identifier that distinguishes you from every other researcher and, through integration in key research workflows such as manuscript and grant submission, supports automated linkages between you and your professional activities ensuring that your work is recognized.

b. Altmetric.com and Altmetric Explorer: Altmetric tracks what people are saying about papers online on behalf of publishers, authors, libraries and institutions. The Altmetric Explorer lets you monitor, search and measure conversations about your publications and those of your competitors. Use the Explorer to deliver insights, track mentions and measure levels of attention over time.

c. Academia.edu Search people, Research interests and Universities.

d. ResearchGate Share your publications, access millions more, and publish your data. Connect and collaborate with colleagues, peers, co-authors, and specialists in your field. Get stats about views, downloads, and citations of your research.

e. LinkedIn the world's largest professional network with 250 million members in over 200 countries and territories around the globe. Connect the world's professionals to make them more productive and successful. When you join LinkedIn, you get access to people, jobs, news, updates, and insights that help you be great at what you do.

f. Publish or Perish (Including H-Index) Publish or Perish is a software program that retrieves and analyzes academic citations. It uses Google Scholar and Microsoft Academic Search to obtain the raw citations, then analyzes these and presents the metrics.

g. CiteULike a free service for managing and discovering scholarly references.

h. Naymz: measure and manage your social reputation

i. figshare Store, share, discover research. Manage your research in the cloud and control who you share it with or make it publicly available and citable.

j. Peer Evaluation Peer evaluation is about giving Open Access to your primary data, working papers, articles, media and having them all reviewed and discussed by your peers.

k. Research Scorecard Is all about facilitating scientific collaborations. This database and data mining tools provide a unique way to assess biomedical scientific and technical expertise, helping researchers find and evaluate potential colleagues and staff. Peer Evaluation is about giving Open Access to your primary data, working papers, articles, media and having them all reviewed and discussed by your peers.

1. Social Science Research Network (SSRN) SSRN is devoted to the rapid worldwide dissemination of 
social science research and is composed of a number of specialized research networks in each of the social sciences.

m. ReaderMeter Research impact, crowdsourced.

n. BiomedExperts Is the first literature-based scientific professional network that brings the right researchers together and allow them to connect, network, communicate and collaborate online.

o. PLoS Impact Explorer This page mashes up altmetrics data from Altmetric with articles from the Public Library of Science (PLoS). Check which articles are seeing the most buzz from social media sites, newspapers and in online reference managers.

p. PaperCritic Offers researchers a way of monitoring all types of feedback about their scientific work, as well as allowing everyone to easily review the work of others, in a fully open and transparent environment. PaperCritic is powered by the Mendeley API.

q. Scholarometer Is a social tool to facilitate citation analysis and help evaluate the impact of an author's publications.

r. Microsoft Academic Search Provides Author metrics + Article metrics

s. Research Blogging Allows readers to easily find blog posts about serious peer-reviewed research, instead of just news reports and press releases.

t. Mendeley Mendeley is a free reference manager that saves you time organizing your documents, writing papers and collaborating with peers.

u. Twitter Social networking and microblogging service utilising instant messaging, SMS or a web interface.

v. Quora Ask any question, get real answers from people with first hand experience, and blog about what you know.

w. SlideShare Upload and share publicly or privately PowerPoint presentations, Word documents and Adobe PDF Portfolios.

x. Flickr Picture galleries available with social networking, chat, groups, and photo ratings.

y. Facebook An online networking service. Connects people with friends and others who work, study and live around them.

z. Altmetrics for Scopus. Can be found in the abstract view of an article, below the Related Documents box in the right-hand column. Altmetrics for Scopus will only appear when data is available.

\section{LIBRARY INVOLVEMENT}

As altmetrics have emerged and continue to grow and evolve, so too has the role that academic librarians play in supporting altmetrics, metrics, and impact, from support to professional use to advocacy. Any librarian in this field will need to continue not only filling these roles, but also ensuring that they themselves are part of the conversation as it moves forward and staying up-to-date with developments within this area.
The concept of library involvement pertaining to metrics did not originate with altmetrics. Impact Factor was originally created primarily for use by librarians in making collection development and retention decisions. Libraries continue to bear primary responsibility for the acquisition of bibliometrics tools, most notably Web of Science, Journal Citation Reports, and Scopus, as well as the training of people in their use. As a result, librarians are already familiar with providing support for these tools, so it makes sense that librarians have expanded to support the variety of altmetrics sources and tools.

Additionally, librarians serve as natural leaders when it comes to altmetrics, not only due to familiarity with resources, but also because of the relationships they maintain with several disparate groups. As a result, librarians serve as a neutral voice and advocate on behalf of the needs of their community, while also providing insight about the tools and metrics they help support through their own experience and expertise.

The following sections detail some specific areas in which libraries and librarians are supporting and interacting with altmetrics.

\section{A. Acquisition, Evaluation and Access}

Despite the fact that some altmetrics tools are primarily marketed toward individual scholars, librarians remain the primary gatekeepers when it comes to acquiring and providing access to resources, as well as deciding which resources best fit the needs of their research community. We have already seen altmetrics begin to shift from free resources to a cost structure, and tools like Altmetric Institutional and PlumX require both a subscription and a level of backend support to be successfully implemented at an institution, roles that libraries are already familiar with providing. Thus, it's likely that libraries will continue to serve as gatekeepers for most altmetrics products. However, for products with less recognition, this may also mean some more aggressive actions to ensure that funding is available and also to increase awareness and use once the tools have been purchased, which brings us to the next role libraries play in altmetrics.

\section{B. Outreach, Training and Marketing}

Librarians are uniquely situated to deliver altmetrics information to researchers and to tailor this information based on the varying needs of their user population. Educating users on library tools is hardly a new role, and as with many outreach efforts, librarians must take care to present the information in a way that best resonates with their users. For many, terms like altmetrics may carry no meaning, conjure up overly narrow meaning which equating altmetrics with Twitter counts, or carry unpleasant associations. For this reason, librarians must be careful to present information regarding altmetrics in an informative 
and accessible way, while also taking care to differentiate it from bibliometrics and other similar concepts.

Research guides are a common way to introduce altmetrics, while also providing links to tools and other helpful sources of information. Other common forms of outreach include workshops, one-on-one appointments with researchers, and online tutorials. Handouts can also be an effective advertising tool. A double-sided handout at Curtin University succinctly explains areas of expertise, summarizes services provided, and provides contact information and links to additional information.

\section{Communication and Advocacy}

While educating users is a vital function of librarians, they are also one of the strongest voices in the altmetrics movement, partly due to their knowledge, but also due to their unique positioning as a neutral voice and central academic hub within their institutions. Additionally, librarians often enjoy open communication lines with many different stakeholders on campus, which places them in a perfect position to facilitate communication when it comes to issues like altmetrics. This means not only communicating with some of those groups individually, but also setting the stage for multiple groups to communicate with each other, directly or indirectly. The following are some specific groups with whom it may be particularly important to communicate and messages that it may be important to impart.

1. FACULTY AND RESEARCHERS: As mentioned above, awareness and understanding of altmetrics, scholarly impact, and related topics is of primary importance, but encouraging faculty and researchers to take a proactive stance among their colleagues and within their departments or research centers can be an effective means of indirect communication. For example, encouraging faculty to take a look at internal procedures for measuring scholarly impact for things like promotion, merit, tenure, or awards can help these groups consider the role altmetrics can or should play in these procedures.

\section{GRADUATE AND UNDERGRADUATE} STUDENTS: Students are an important demographic, since today's students become tomorrow's researchers and are still developing their research skills, so they are often open to incorporating new ideas into their research practice. Since they are often in close contact with other researchers, students can also be effective advocates for altmetrics tools and principles.

3. ADMINISTRATORS: Research metrics are often used in evaluation decisions, and administrators are often in the position to serve as decision makers. An understanding of altmetrics can help in securing funds necessary to purchase and implement an institutional altmetrics tool and also ensures that altmetrics are used appropriately in the decisionmaking process. After all, encouraging faculty to incorporate altmetrics into their procedures and files (such as files for tenure) is ineffective if the evaluators reading the file cannot correctly interpret these metrics or misunderstand the context in which they are being delivered.

\section{PUBLISHERS AND TOOLMAKERS:}

Librarians don't often think of publishers and toolmakers as a group in need of communication after all, the companies that provide library tools are often in steady contact with libraries. However, a good relationship means developing two way communication so that we are not only aware of developments from the publishers and toolmakers, but also providing feedback on these tools based on our own observations as well as the needs of the users we serve. As with many aspects of modern scholarship, publishers are unsure about the future of altmetrics or what they mean for publishers. Encouraging practices like the creation of freely available article-level metrics or the incorporation of tools like the Altmetric donut can influence the altmetrics landscape while also helping researchers measure their scholarship in different ways.

\section{Collection Development}

The idea of using research metrics for their original purpose seems almost foreign in today's scholarly landscape, but metrics still serve as a powerful indicator of journal usage and impact. While librarians may be more familiar with using locally collected usage data, such as COUNTER data, careful application of altmetrics can give librarians additional perspective that can be used to make collection decisions such as journal cancellations. One tool that's particularly effective in this regard is Altmetric Explorer. One of the primary purposes of this tool is to help librarians evaluate journals, with the ability to explore altmetrics based data and create custom reports. Some researchers even advocate for incorporation of altmetrics like CiteULike's social bookmarks or Mendeley's readership metrics into journal evaluation decisions.

\section{E. Integration with Library Tools}

One aspect of altmetrics that has excited many librarians is the ability to incorporate them into existing library tools, most notably institutional repositories. This provides an opportunity to not only bring renewed interest and attention to existing institutional repositories, but also provide an incentive for researchers to deposit their scholarship into a repository, as it can give them access to metrics that may be otherwise unavailable. These same metrics can, in turn, also give librarians additional tools for the evaluation of their own institutional repository. Two notable tools that offer 
some level of integration with institutional repositories are Altmetric and PlumX. Both make altmetrics data available for individual pieces of scholarship with DOIs or other digital identifiers-Altmetric through its distinctive donut, which can be displayed when viewing an item record within the institutional repository, and PlumX through the PlumX interface, which reports institutional repository metrics for all items, as well as for individual items.

\section{F. Scholarly Research}

Librarians who have gained familiarity with altmetrics are well-poised to then actively contribute to the scholarly landscape. The idea of focusing scholarly research on metrics isn't new, as a number of librarians have published articles related to bibliometrics within the past twenty years, so altmetrics research is a natural extension of the same research area. A number of librarians have already given presentations and written articles, white papers, and books on the subject of altmetrics, some of which are detailed below. As the library professional explored, a number of areas related to altmetrics are in need of more scholarly research and communication, including the integration of altmetrics into libraries and institutions and both research focused and practical applications of altmetrics.

\section{G. Self Evaluation}

Finally, librarians are not only educating others about altmetrics and integrating altmetrics into library tools, but are acting as consumers of altmetrics by using these metrics for their own purposes. Librarians tend to be particularly well situated to benefit from altmetrics since altmetrics provide a mechanism for the quantitative measurement of some scholarly activities with a few methods for evaluative measures, such as the tracking of Twitter comments and conversations during a professional presentation or regarding a scholarly blog posting.

\section{WAYS TO CONTINUE UP TO DATE}

Given the quickly changing nature of altmetrics, librarians and library administrators wishing to stay on top of recent developments must be proactive in seeking out information since a variety of venues bring different perspectives on the latest activities and trends within altmetrics. The following represent many of these differing viewpoints, but the list is far from exhaustive.

1. Customized Google News: The popular treatment of altmetrics gives important insight into the translation of this topic beyond the academic realm and often gives hints at the more general and public perspective, along with practical applications of theoretical topics. Google News can be customized for a variety of topics and sources, such as developing a News alert with an altmetrics focus, along with other topics of interest, is relatively easy but does require a Google login to save. An RSS feed can also be created based on the personalized
Google News selections. While Google Scholar searches can be a valuable way to discover many altmetrics publications that fall outside the realm of traditional databases, including white papers, prepublication manuscripts in arXiv, and non indexed journals, Google Scholar can also be set up to periodically send e-mails on topics of interest. These options are available in the Alerts option when logged in to Google Scholar. More sophisticated search terms such as scientometrics, semantometrics, altmetrics and libraries, or altmetrics and institutional repositories are appropriate for these alerts, based on your specific interests.

2. ARL Publication Alerts: While less customizable than the previous two examples, ARL publications are an excellent way to keep up with the latest news, reports, research, and events related to the top research libraries in the United States and include many areas of interest to research libraries, including altmetrics and research impact. There are multiple ways to receive alerts, including signing up for the ARL e-newsletter and receiving updates through Google+, Facebook, or Twitter or directly from the ARL home page.

3. Toolmaker and Scholarly Blogs: Practically all of the altmetrics toolmakers have developed blogs, which are regularly updated with news items, feedback, questions, and special looks at specific aspects of altmetrics and related issues. These blogs often feature posts directly targeted toward librarians and can also serve as sources. In addition to toolmaker blogs, a number of scholarly blogs serve a much-needed role within academia in providing news, opinions, and thoughtful analysis on a number of issues. There are a wide variety of scholarly blogs that serve different purposes and are written from different perspectives. Some have been created by individuals, others have a number of contributors, and others represent a company or organization. Similarly, they cover different aspects of academia, with some specializing in particular aspects, while others represent a broader view. Therefore, these blogs have all covered altmetrics information, trends, and applications to academic research in a meaningful way, but from different viewpoints and with different intended audiences.

4. Presentations, Workshops, and Invited Speakers: Often, the most useful and up-to-date information tailored to an academic library audience can be obtained through in-person presentations. Within the past two years, the topic of altmetrics has been covered at many prominent library conferences. ACRL, ALA, Charleston, and Internet Librarian International have all featured presentations from librarians; altmetrics tool providers like Altmetric, PLOS, and PlumX; and organizational bodies like NISO. Additionally, several nonlibrary conferences have a strong 
altmetrics interest. These conferences focus more heavily on the information science and technical perspective, but they represent some of the most cutting-edge altmetrics developments. Finally, consider hosting your own event to increase knowledge locally.

5. Books: Altmetrics has reached the point in development where there is now enough information and relative stability for monographic publications.

\section{CONCLUSION}

In this article reviewed the various activities in which librarians have engaged with reference to altmetrics, from providing access to the tools that encourage deeper analysis of scholarly impact to the use of altmetrics for their own core activities within research and collection development. However, with greater knowledge of the field both possible and practical, librarians are increasingly well positioned to serve an even wider variety of roles, such as that of educators and information supporters, direct consumers of altmetrics, and facilitators who create opportunities for discourse and debate. For many, the field of altmetrics continues to be a source of uncertainty and confusion, with changes seeming to occur practically on a daily basis. Nevertheless, the potential value of altmetrics to users of all kinds makes the involvement of knowledgeable parties like librarians a worthwhile investment, not only in the future of the field, but also in the future of academic impact, scholarly communication, and intellectual diversity.

\section{REFERENCES}

[1] E. Garfield, "Journal Impact Factor: A Brief Overview," Canadian Medical Association Journal 161(8), 979-80,

[2] Haustein, S., Peters, I., Sugimoto, C.R., Thelwall, M., \& Larivière, V. (2014). Tweeting biomedicine: An analysis of tweets and citations in the biomedical literature. Journal of the Association for Information Science and Technology, 65(4), 656-669.

[3] Holmberg, K., \& Thelwall, M. (2014). Disciplinary differences in Twitter scholarly communication. Scientometrics

[4] Konkiel, S. (2012). Robust 'altmetrics' as a framework for measuring item usage and researcher impact in institutional repositories. Poster presentation at 2012 LITA National Forum. Columbus, OH, USA. 5-7 October 2012

[5] Mohammadi, E. \& Thelwall, M. (in press). Mendeley readership altmetrics for the social sciences and humanities: Research evaluation and knowledge flows. Journal of the Association for Information Science and Technology.

[6] Peters, I., Jobmann, A., Eppelin, A., Hoffmann, C. P., Künne, S., \& Wollnik-Korn, G. (2014). Altmetrics for large, interdisciplinary research groups: A case study of the Leibniz Association. In Proceedings of Libraries in the Digital Age, Zadar, Croatia. $\quad$ Retrieved from http://ozk.unizd.hr/proceedings/index.php/lida/article/view/162/1 38

[7] Priem, J., Taraborelli, D., Groth, P., \& Neylon, C. (2011) Altmetrics: A manifesto. Version 1.01, September 28, 2011. Retrieved from altmetrics.org/manifesto

[8] Sud, P., \& Thelwall, M. (2014). Evaluating altmetrics. Scientometrics, 98(2), 1131-1143.

[9] Thelwall, M. (2009). Introduction to Webometrics: Quantitative Web Research for the Social Sciences. San Rafael, CA: Morgan \& Claypool.

[10] Thelwall, M., Haustein, S., Larivière, V., \& Sugimoto, C. R. (2013). Do altmetrics work? Twitter and ten other social web services. PloS ONE, 8(5), e64841.

[11] Zahedi, Z., Fenner, M., \& Costas, R. (2014). How consistent are altmetrics providers? Study of 1000 PLOS ONE publications using the PLOS ALM, Mendeley and Altmetric.com APIs. In: altmetrics 14. Workshop at the Web Science Conference. 